\title{
Article
}

\section{Nature of PO Bonds in Phosphates}

Benjamin Gamoke, Diane Neff, and Jack Simons

J. Phys. Chem. A, 2009, 113 (19), 5677-5684• Publication Date (Web): 20 April 2009

Downloaded from http://pubs.acs.org on May 12, 2009

\section{More About This Article}

Additional resources and features associated with this article are available within the HTML version:

- Supporting Information

- Access to high resolution figures

- $\quad$ Links to articles and content related to this article

- Copyright permission to reproduce figures and/or text from this article

\section{View the Full Text HTML}




\title{
Nature of PO Bonds in Phosphates
}

\author{
Benjamin Gamoke, Diane Neff, and Jack Simons* \\ Chemistry Department and Henry Eyring Center for Theoretical Chemistry, \\ University of Utah, Salt Lake City, Utah 84112
}

Received: November 13, 2008; Revised Manuscript Received: March 31, 2009

\begin{abstract}
Making use of a combination of ab initio calculated geometries, orbital energies, and orbital spatial distributions as well as experimental information about bond lengths, bond energies, vibrational frequencies, and dipole moments, the nature of the terminal $\mathrm{PO}$ bond in phosphates such as $(\mathrm{MeO})_{3} \mathrm{PO}$ was probed and compared to the case in $\mathrm{MeO}-\mathrm{P}=\mathrm{O}$ where $\mathrm{P}$ is trivalent and a $\mathrm{PO} \pi$ bond is thus assumed to exist. We find that the $\mathrm{MeO}-\mathrm{P}$ and terminal $\mathrm{PO}$ bond lengths in $(\mathrm{MeO})_{3} \mathrm{PO}$ are essentially the same as in $\mathrm{MeO}-\mathrm{P}=\mathrm{O}$ and the terminal $\mathrm{PO}$ lengths are substantially shorter than single $\mathrm{P}-\mathrm{OMe}$ bond lengths. We also find that the HOMO orbital energies in the two compounds are within $0.1 \mathrm{eV}$ of one another and that these orbitals have spatial characteristics much like one would expect of a bonding $\pi$ orbital connecting two atoms from different rows of the periodic table. Using this data, making a comparison to the more familiar bonding arising in $\mathrm{N}_{2}, \mathrm{CO}$, and $\mathrm{BF}$, and taking note of the dipole moments in compounds known to possess dative bonds, we conclude that it is best to represent the terminal PO bond in phosphates in terms of valence-bond structures such as $(\mathrm{MeO})_{3} \mathrm{P}=\mathrm{O}$ in which the formal charges are $\mathrm{P}^{0} \mathrm{O}^{0}$ and where a single $\mathrm{PO} \pi$ bond exists. However, when it comes to characterizing the $\mathrm{PO}$ antibonding $\pi^{*}$ orbitals, significant differences arise. Electronic structure methods were able to identify the $\pi^{*}$ orbital of $\mathrm{MeO}-\mathrm{P}=\mathrm{O}$ and to determine its energy (the $\mathrm{MeO}-\mathrm{P}=\mathrm{O}^{-}$ anion is even bound). Similar attempts to identify the $\mathrm{PO} \pi^{*}$ orbital in the unbound $(\mathrm{MeO})_{3} \mathrm{P}=\mathrm{O}^{-}$anion lead us to conclude that this anion state is probably so strongly coupled to the continuum (i.e., to states corresponding to $(\mathrm{MeO})_{3} \mathrm{P}=\mathrm{O}$ plus a free electron) that it is so short lived as to be undetectable in experiments.
\end{abstract}

\section{Introduction}

The purpose of this paper is to elucidate the nature of the bonding that exists between phosphorus and oxygen atoms in compounds containing the phosphate motif. This work was inspired by a recent joint experimental-theoretical study ${ }^{1}$ that probed the unique PO bond in molecules such as ( $\left.\mathrm{ROR}^{\prime} \mathrm{OR}^{\prime \prime} \mathrm{O}\right) \mathrm{PO}$. In ref 1 , electron transmission spectroscopy (ETS) data were used to look for evidence of anionic states involving an electron attached to an antibonding PO $\pi^{*}$ orbital. The signatures expected to characterize this class of states include an ETS spectral feature at relatively low electron kinetic energy (because $\pi^{*}$ orbitals are expected to have low energies) having a sufficiently small width (i.e., energy uncertainty) to suggest that the electron-attached resonance state has a substantial lifetime. The evidence presented ${ }^{1}$ suggested that there is little evidence for a long-lived anion state of $\pi^{*}$ character in phosphatecontaining molecules. This fact, thus, brings into question the use of chemical formulas such as $(\mathrm{HO})_{3} \mathrm{P}=\mathrm{O}$ for phosphoric acid, which implies that a PO $\pi$ bond exists. That is, if the experimental facts suggest there is no PO $\pi^{*}$ orbital, can there be a PO $\pi$ orbital and thus a PO $\pi$ bond?

In attempting to find and characterize $\pi$ and $\pi^{*}$ orbitals, one has to be careful. In the examples at hand, species possessing the putative $\mathrm{P}=\mathrm{O}$ bonding motif, it is the $\pi^{*}$ orbital belonging to the $\pi^{2} \pi^{* 1}$ anionic electronic state that we are probing because of the nature of the experiments. ${ }^{1}$ This is not the same $\pi^{*}$ orbital occupied in a $\pi^{1} \pi^{* 1}$ excited state of the neutral. In the anion, the $\pi^{*}$ orbital is expected to be higher in energy and considerably more diffuse than the $\pi^{*}$ orbital in the $\pi^{1} \pi^{* 1}$ neutral,

* To whom correspondence should be addressed. E-mail: simons@ chem.utah.edu. Web site: http://simons.hec.utah.edu.

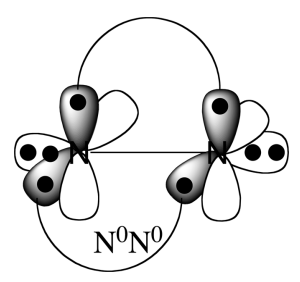

Figure 1. Dominant valence-bond structure for $\mathrm{N}_{2}$ showing the formal charge state on each atom, two lone pairs, one $\sigma$ bond, and two $\pi$ bonds.

because the anion $\pi^{*}$ orbital experiences Coulomb and exchange interactions with two electrons in the underlying $\pi$ orbital, whereas, in the neutral, only one electron occupies the underlying $\pi$ orbital. In addition, the anion $\pi^{*}$ orbital may have such a short lifetime (n.b., the $\pi^{2} \pi^{* 1}$ states are unstable with respect to electron loss) that its experimental identification and theoretical characterization are futile (i.e., a short lifetime produces a broad energy uncertainty that may obliterate any spectral signature).

A. Overview of Well-Understood Bonding Paradigms. Before considering the nature of the bonding in phosphates, let us consider the bonding in a few more familiar cases taking into account the electronegativity difference between the atoms involved in the bonds as well as the degree of spatial overlap of the atomic orbitals producing the bonds and how to account for lone pairs of electrons. We begin with the $\mathrm{N}_{2}$ molecule where most chemists would agree a triple bond exists and would describe the bonding in terms of the dominant valence-bond structure shown in Figure 1.

In this figure, as in others to follow, we show the $\sigma$ bond as a single line (the two electrons shared in this bond are not 


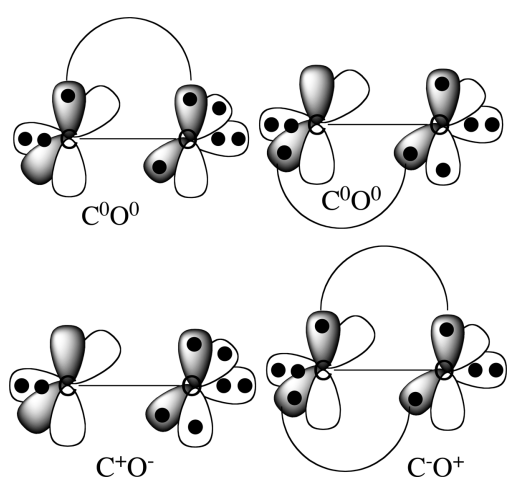

Figure 2. Valence-bond structures for $\mathrm{CO}$ showing formal charges, lone pair electrons, and $\pi$ bonds.

shown), while the two $\pi$ bonds and the shared electrons forming them are designated with curved lines connecting the two atomic orbitals that form the bond and with dots, respectively. The formal charges (zero in this case for each $\mathrm{N}$ atom) are computed by taking the number of valence electrons (five for each $\mathrm{N}$ ) and subtracting the number of lone-pair electrons (two for each $\mathrm{N})$ and subtracting the number of pairs of electrons shared in the bonds (three for each $\mathrm{N}$ ).

Now, let us contrast the $\mathrm{N}_{2}$ case to those of $\mathrm{CO}$ and $\mathrm{BF}$, both of which are isoelectronic with $\mathrm{N}_{2}$. In Figure 2, we see four valence-bond structures for $\mathrm{CO}$. The first two have one $\sigma$ and one $\pi$ bond and assign zero formal charges to $\mathrm{C}$ and $\mathrm{O}$. The third has no $\pi$ bond and formal charges of $\mathrm{C}^{+}$and $\mathrm{O}^{-}$, while the fourth has two $\pi$ bonds and $\mathrm{C}^{-}$and $\mathrm{O}^{+}$as formal charges.

There are two reasons we need to consider more than one valence-bond structure when discussing $\mathrm{CO}$. First, the difference in electronegativity (B has electronegativity 2.0, C 2.5, N 3.0, $\mathrm{O} 3.5$, and $\mathrm{F} 4.0$ ) between $\mathrm{C}$ and $\mathrm{O}$ is large enough that the two ionic structures shown in Figure 2 can make substantial contributions to the bonding. In $\mathrm{N}_{2}$, valence-bond structures corresponding to $\mathrm{N}^{+} \mathrm{N}^{-}$and $\mathrm{N}^{-} \mathrm{N}^{+}$are not impossible, but they play much less of a role in the wave function so they need not be considered. Second, there is no single $\mathrm{C}^{0} \mathrm{O}^{0}$ structure that would offer a qualitatively correct picture of the bonding in CO. Each of the two shown in Figure 2 suggests that a single $\pi$ bond is formed, that two lone pairs are held on the $\mathrm{O}$ atom, and that the $\mathrm{C}$ atom has one vacant $2 \mathrm{p}$ orbital. However, the two structures differ in terms of which orbitals are vacant, which contain the lone pairs, and which are involved in the $\pi$ bond. Obviously, these two $\mathrm{C}^{0} \mathrm{O}^{0}$ valence-bond structures are degenerate yet independent contributors to the wave functions.

As discussed long ago by Pauling, ${ }^{2}$ an analysis of the bond length and dipole moment in $\mathrm{CO}$ suggests that the $\mathrm{C}^{-} \mathrm{O}^{+}$triplebond structure contributes ca. $50 \%$, the two $\mathrm{C}^{0} \mathrm{O}^{0}$ double-bond structures $20 \%$ each, and the $\mathrm{C}^{+} \mathrm{O}^{-}$structure $10 \%$ to the full wave function. As a result, Pauling assigns (see p 266 of ref 2) a bond order of $2.4(0.5 \times 3+2 \times 0.2 \times 2+0.1 \times 1=2.4)$ to $\mathrm{CO}$. Note that the $\mathrm{C}^{-} \mathrm{O}^{+}$structure, which allows a lone pair of electrons to be donated from $\mathrm{O}$ to $\mathrm{C}$ to form two $\pi$ bonds, contributes more than the $\mathrm{C}^{+} \mathrm{O}^{-}$structure even though $\mathrm{C}$ is less electronegative than $\mathrm{O}$. The formation of the $\pi$ bonds is what drives overcoming the electronegativity difference.

When considering reasonable valence-bond structures for the BF molecule, we arrive at the four shown in Figure 3. In the first, the $\mathrm{B}$ and $\mathrm{F}$ atoms have formal charges of zero, contain no $\pi$ bonds, and place three lone pairs on the $\mathrm{F}$ atom, while the second $\left(\mathrm{B}^{2-} \mathrm{F}^{+2}\right)$ structure has two $\pi$ bonds and one lone pair on $\mathrm{F}$. The two $\mathrm{B}^{-} \mathrm{F}^{+}$structures each contain one $\pi$ bond and place two lone pairs on the $\mathrm{F}$ atom.

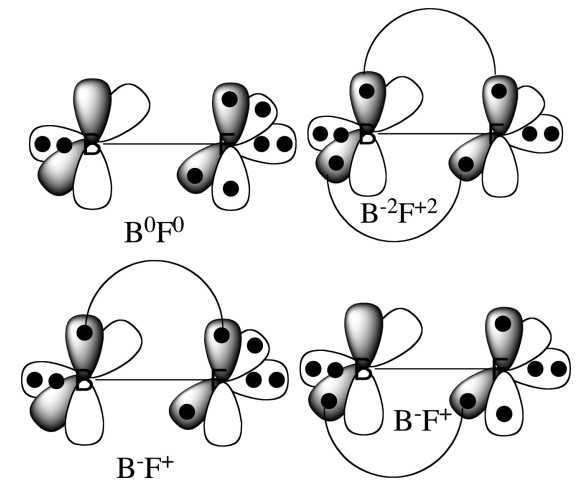

Figure 3. Valence-bond structures for BF showing formal charges, lone pair electrons, and $\pi$ bonds.

Because of the much larger electronegativity difference in the $\mathrm{BF}$ case (B and $\mathrm{F}$ have electronegativities of 2.0 and 4.0, respectively) compared to $\mathrm{CO}$, the second structure in which two $\pi$ bonds occur is a minor contributor to the wave function for $\mathrm{BF}$. As mentioned earlier, the analogous $\mathrm{C}^{-} \mathrm{O}^{+}$structure in $\mathrm{CO}$ contributed $50 \%$ to the wave function. Also, because of the large elelctronegativity difference in $\mathrm{BF}$, the third and fourth structures are also minor contributors. So, the $\mathrm{B}^{0} \mathrm{~F}^{0}$ structure is dominant in this case where the electronegativity difference is so large. As a result, the equilibrium bond length ${ }^{3}$ in $\mathrm{BF}\left(r_{\mathrm{e}}=\right.$ $1.26 \AA$ ) is only slightly shorter than the sum of single-bond $\operatorname{radii}^{4}(0.84 \AA$ for $\mathrm{B}$ and $0.57 \AA$ for $\mathrm{F})$; in other words, in $\mathrm{BF}$ a single $\sigma$ bond exists and there is little contribution from $\pi$ bonding. In contrast, for $\mathrm{CO}$ and $\mathrm{N}_{2}$, the bond lengths ${ }^{3}$ are 1.13 and $1.09 \AA$, respectively. These distances are significantly shorter than the sums of the single-bond $\operatorname{radii}^{4}(0.71 \AA$ for $\mathrm{N}$, $0.76 \AA$ for $\mathrm{C}$, and $0.66 \AA$ for $\mathrm{O}$ ), which is in line with the dominance of valence-bond structures having substantial $\pi$ bonding in these two diatomics.

In summary, considerations of how atom pairs share electrons to different degrees on the basis of their electronegativity differences and on how many valence electrons each atom possesses leads us to focus on certain dominant valence-bond structures for each bond type. When applied to the $\mathrm{N}_{2}, \mathrm{CO}$, and $\mathrm{BF}$ isoelectronic series, the predictions result in valencebond-structure averaged bond orders of 3, 2.4, and 1, respectively.

B. Possible Bonding Paradigms in Phosphates. Let us now consider what valence-bond structures might be reasonable to suggest when considering bonds between $\mathrm{P}$ and $\mathrm{O}$ atoms, keeping in mind that oxygen has six valence electrons and that phosphorus has five and is known to form both tri- and pentavalent compounds. In Figure 4, several candidate structures are shown, the first two of which have phosphorus in a trivalent state and the third of which is an alternative valence-bond structure to the second. The valence states of phosphorus in the other compounds are the subject of this study and thus will be discussed later.

In the first molecule, ${ }^{5} \mathrm{P}$ has a lone pair and forms one $\sigma$ bond to each of three oxygen atoms, the $\mathrm{P}$ atom uses its $3 \mathrm{~s}$ and three $3 \mathrm{p}$ orbitals to form the lone-pair and $\sigma$-bond orbitals, and both $\mathrm{P}$ and $\mathrm{O}$ have formal charges of zero. In the second structure, the $\mathrm{P}$ is $\sigma$-bonded to an $\mathrm{O}$ atom of an $\mathrm{OH}$ group and $\sigma$ - and $\pi$-bonded to another $\mathrm{O}$ atom; the $\mathrm{P}$ atom uses its $3 \mathrm{~s}$ and two of its $3 p$ orbitals to form the two $\sigma$ bonds and to hold the lone pair and uses its fourth $3 p$ orbital to form the $\pi$ bond. In the third structure, the same $\mathrm{HO}-\mathrm{PO}$ molecule is described in terms of a $\sigma$ bond connecting $\mathrm{P}$ and $\mathrm{OH}$, a $\sigma$ bond connecting $\mathrm{P}$ and $\mathrm{O}$, but with $\mathrm{P}$ in a +1 formal charge state and the terminal $\mathrm{O}$ in a -1 charge state. Here, $\mathrm{P}^{+}$uses its $3 \mathrm{~s}$ and two of its $3 \mathrm{p}$ 


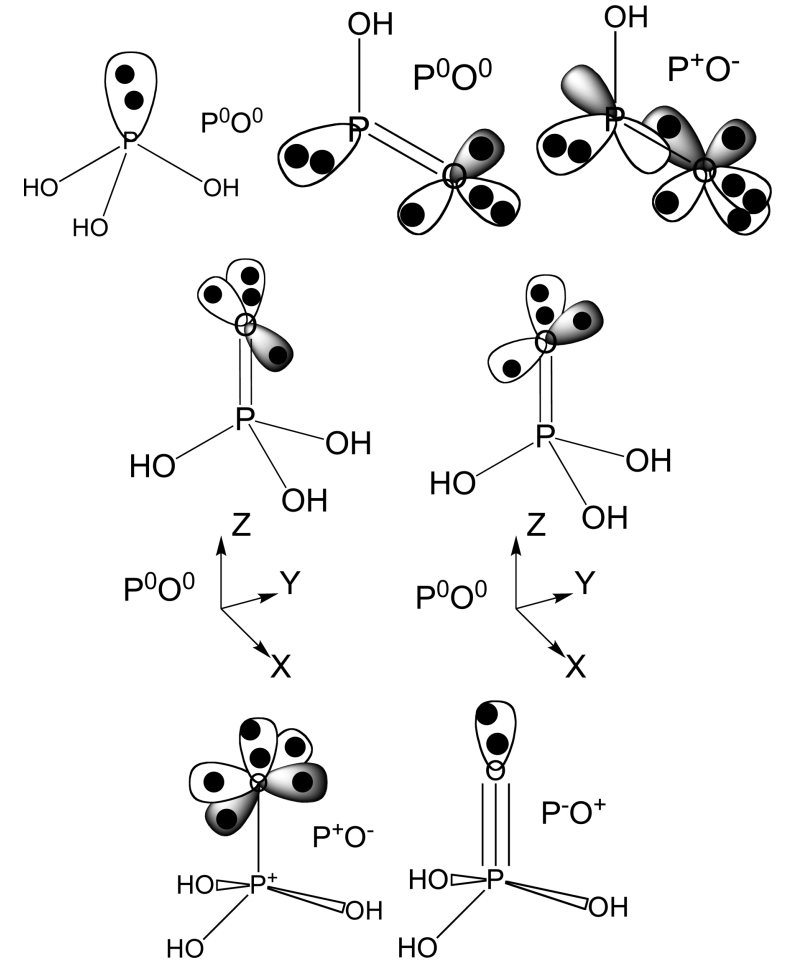

Figure 4. Valence-bond structures for various $\mathrm{P}$ - and O-containing compounds showing formal charges, some lone pair electrons, and possible $\mathrm{PO} \pi$ bonds.

orbitals to form the two $\sigma$ bonds and to accommodate the lone pair but has its fourth $3 p$ orbital empty. Of the two valencebond structures shown for $\mathrm{HO}-\mathrm{PO}$, the first is assumed to be dominant because this molecule is assumed to contain a $\mathrm{P}=\mathrm{O}$ $\pi$ bond. The third structure corresponds to a dative bond between $\mathrm{P}^{+}$and the terminal $\mathrm{O}^{-}(\mathrm{HO}-\mathrm{P} \rightarrow \mathrm{O})$ with the $\mathrm{P}$ atom also holding a lone pair and having a vacant $3 p$ orbital into which some back-donation from an $\mathrm{O} 2 \mathrm{p}$ orbital may take place.

In support of the claim made above that a $\mathrm{P}=\mathrm{O} \pi$ bond exists in $\mathrm{HO}-\mathrm{PO}$, we note that the $\mathrm{P}-\mathrm{OH}$ bond length in $\mathrm{HO}-\mathrm{PO}$ is ca. $1.66 \AA$, while its terminal PO bond length is $1.52 \AA$. We also point out that the single-bond radii $^{4}$ of $\mathrm{P}$ and $\mathrm{O}$ are 1.07 and $0.66 \AA$, respectively, while the corresponding electronegativities are 2.1 and 3.5. So, the PO bond of length $1.5 \AA$ is certainly much shorter than the sum of the two single-bond radii, while the $\mathrm{P}-\mathrm{OH}$ bond is just a bit shorter than this sum. At first, the $1.5 \AA \mathrm{PO}$ bond length seems to suggest that a $\pi$ bond (as in the first valence-bond structure for $\mathrm{HO}-\mathrm{PO}$ in Figure 4) is present. However, this fact could also be consistent with bond contraction due to attraction of the $\mathrm{P}^{+}$and $\mathrm{O}^{-}$centers (as in the second (dative) $\mathrm{HO}-\mathrm{PO}$ valence-bond structure in Figure 4). We will have more to say about how bond lengths, infrared (IR) vibrational frequencies, and bond-dissociation energies offer support for or evidence against the existence of $\pi$ bonding in this and the phosphate species discussed here.

The bottom four structures in Figure 4 offer alternative valence-bond descriptions for the bonding in phosphoric acid $\mathrm{H}_{3} \mathrm{PO}_{4}$. They differ in the extent to which the $\mathrm{P}$ and the unique $\mathrm{O}$ atom share electrons to form $\pi$ bonds. The first two have formal charges of zero for both $\mathrm{P}$ and $\mathrm{O}$, a single $\mathrm{PO} \pi$ bond, and describe the unique $\mathrm{O}$ atom as having two lone pairs. These two structures only differ in terms of which oxygen $2 p$ orbital contains a lone pair and thus is not involved in the PO $\pi$ bond. The first uses its $2 \mathrm{p}_{y}$ orbital in the $\pi$ bonding and holds a lone pair in its $2 \mathrm{p}_{x}$ orbital; in the other structure, the roles of the $2 \mathrm{p}_{x}$ and $2 \mathrm{p}_{y}$ orbitals are reversed. Please note the analogous roles played by these two $\mathrm{P}^{0} \mathrm{O}^{0}$ structures and the two $\mathrm{C}^{0} \mathrm{O}^{0}$ structures shown in Figure 2 for $\mathrm{CO}$, because we have more to say about these similarities later. Continuing, the third structure (bottom left in Figure 4) describes the bonding in terms of $\mathrm{P}^{+}$and $\mathrm{O}^{-}$ ionic bonding, has no $\pi$ bond, and causes the unique $\mathrm{O}$ atom to have three lone pairs. This structure can also be written in terms of the dative-bond notation $(\mathrm{HO})_{3} \mathrm{P} \rightarrow \mathrm{O}$. The fourth (bottom right) is the most unusual of the three valence-bond structures; it has formal charges $\mathrm{P}^{-}$and $\mathrm{O}^{+}$and two $\mathrm{PO} \pi$ bonds and retains only one lone pair on the unique $\mathrm{O}$ atom. In the first, second, and fourth structures for $\mathrm{H}_{3} \mathrm{PO}_{4}$, it is natural to inquire about the nature of the atomic orbitals the $\mathrm{P}$ atom is using to share the electron pair(s) involved in the one (first and second structures) or two (fourth structure) $\pi$ bonds. Later in this paper, we address this issue by displaying results of calculations in which the $\mathrm{P}$ atom is allowed to make use of its $3 \mathrm{~d}_{x, z}$ and $3 \mathrm{~d}_{y, z}$ orbitals and results when these $3 \mathrm{~d}$ orbitals are absent (i.e., where we eliminate them from the basis set).

Having introduced the reader to expectations of what might be found when we make use of ab initio theoretical methods to examine the bonding in compounds containing the phosphate motif, we now detail the methods used in section II and then present our results in section III. Finally, section IV contains an overview and our summary.

\section{Methods}

We performed all of our calculations at the restricted (for closed-shell species) and unrestricted (for the anionic species) second-order Møller-Plesset (MP2 or UMP2) level of theory using aug-cc-pVDZ basis sets ${ }^{6}$ on all atoms. Because the methods we used may involve unrestricted wave functions, it is important to make sure that little artificial spin contamination enters into the final wave functions. We computed $\left\langle S^{2}\right\rangle$ for species studied in this work and found values not exceeding (before annihilation) the expected value of $S(S+1)=0.75$ by more than 0.01 for the anionic doublets.

In all of the calculations discussed below, the geometries used were obtained as follows:

1. For the parent neutral molecules, the geometry was optimized at the MP2 level.

2. For the electron-attached species, the geometry of the neutral was used, although the UMP2 method was used to evaluate the anion's energy and orbitals. This choice of geometry was made to allow us to determine the energy gained upon vertical attachment of an electron.

So, the results that we report below pertain to geometries optimized for the neutral species, but the energies of the neutral and anionic species were computed at the HF and UMP2 levels separately. When we display orbitals of an electron-attached species, we are showing the UHF orbitals of the anion.

The experiments of ref 1 on the anionic species that we study here are formed by colliding an electron of specified kinetic energy KE with a gas-phase sample containing the neutral parent molecule. Due to the nature of these experiments, the anions formed in such capture processes have energies lying above the energy of the neutral by an amount equal to the electron's kinetic energy. As such, they are metastable anions that can spontaneously eject their excess electrons, so they have finite lifetimes with respect to this autodetachment process. The energy of the electron-attached state is reflected in a spectral feature of the ETS spectrum with the lifetime of the metastable-anion state determining (via Heisenberg uncertainty) the energy width 
of the corresponding spectral feature. Short lifetimes give broad features, while long-lived states produce sharper features.

To describe such metastable states using ab initio electronic structure theory is not straightforward, because most such methods are based upon variational treatments ${ }^{7}$ of the neutral and anionic electronic states. A variational treatment of metastable anions is plagued by the so-called variational collapse problem. For example, if one carries out such a calculation on the $(\mathrm{MeO})_{3} \mathrm{PO}^{-}$anion using a very large atomic orbital basis set, one will find that the excess electron occupies a molecular orbital $\phi$ that is localized far outside the framework of the $(\mathrm{MeO})_{3} \mathrm{PO}$ molecule. Moreover, one finds an energy for the $(\mathrm{MeO})_{3} \mathrm{PO}^{-}$anion that is only slightly above that of neutral $(\mathrm{MeO})_{3} \mathrm{PO}$. Improving the basis set by adding more and more basis functions of larger and larger radial extent causes $\phi$ to have its major amplitude even further from the molecular framework and the anion's energy to be even closer to (albeit above) that of the neutral. These variational solutions arise because the lowest-energy state of the anion is a wave function describing $(\mathrm{MeO})_{3} \mathrm{PO}$ plus an electron infinitely far away and with no kinetic energy.

Therefore, a straightforward calculation with a large radially flexible basis set will produce a state corresponding to the neutral molecule plus the excess electron very far away. One might be tempted to perform a conventional (e.g., HF, DFT, or MP2) calculation using a basis set that excludes radially diffuse functions, but this too is fraught with danger. How do you know which functions to exclude (to forbid autodetachment) and which to include (to adequately describe the neutral molecule's orbitals)? If too many diffuse basis functions are used, the lowenergy solutions will correspond to a neutral molecule with an electron far away and with low kinetic energy. If too few diffuse functions are used, one will obtain an inadequate description of the larger-r part of the metastable state.

To handle these metastable shape resonances, we have made use of an approach ${ }^{8}$ in which we artificially increase, by a small amount $\delta q$, the nuclear charges of the atoms (the phosphorus and oxygen atoms for the phosphates studied here) involved in binding the electron and carry out the UMP2 calculations on the anion with these artificial nuclear charges. If $\delta q$ is large enough, the attractive potential will be strong enough to shift the metastable state's energy downward enough to render this state bound, square integrable, and thus amenable to study using these conventional variational tools. In contrast, the states describing the neutral molecule plus a free electron will be less affected by the increased nuclear charges because most of their amplitudes occur at large-r. By plotting the energies of the electron-attached state relative to that of the parent neutral species for several values of the charge increment $\delta q$ (but only for values of $\delta q$ for which the anion is bound) and extrapolating to $\delta q=0$, we are able to obtain our approximations to the true energies of these metastable states. We call this the charge stabilization method that was pioneered in ref 8 .

Finally, we note that all calculations were performed using the Gaussian 03 suite of programs, ${ }^{9}$ and the three-dimensional plots of the molecular orbitals were generated with the MOLDEN program ${ }^{10}$ within which we employed the same settings (iso $=0.03$, edge $=19$ ) for all of the orbital plots shown here in order to allow the reader to reliably compare one orbital plot to another.

\section{Results}

A. Compound That Is Assumed to Have a PO $\boldsymbol{\pi}$ Bond. In Figure 5, we show the PO $\pi$ and $\pi^{*}$ orbitals for the compound $\mathrm{H}_{3} \mathrm{C}-\mathrm{O}-\mathrm{PO}$ (the methyl substituted analog of the second

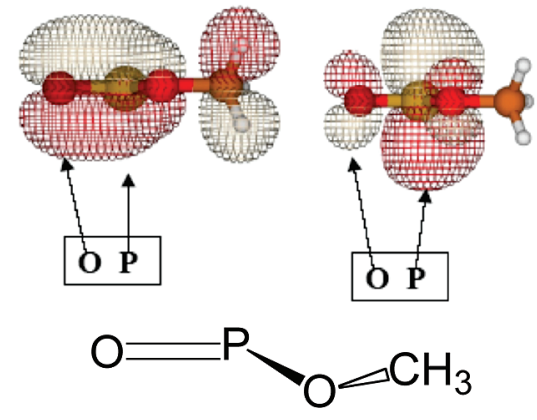

Figure 5. Plots of the PO $\pi$ (left) and PO $\pi^{*}$ (right) orbitals of $\mathrm{H}_{3} \mathrm{C}-\mathrm{O}-\mathrm{P}=\mathrm{O}$ with their oxygen and phosphorus regions labeled. The two $\mathrm{O}$ atoms and the $\mathrm{P}$ atom lie in a plane directed out of the plane of the figure as suggested in the bottom drawing.

compound shown in Figure 4). Our purpose in displaying these orbitals is to show what traditional (i.e., based upon phosphorus $3 \mathrm{p}$ and oxygen $2 \mathrm{p}$ orbitals) PO $\pi$ and $\pi^{*}$ orbitals are expected to look like.

The PO $\pi$ orbital shown at the left has a nodal plane containing the $\mathrm{P}-\mathrm{O}$ bond axis, has density localized on and between the $\mathrm{P}$ and terminal $\mathrm{O}$ atoms, and has an orbital energy of $-12.6 \mathrm{eV}$. The corresponding $\pi^{*}$ orbital has a nodal plane containing the $\mathrm{P}-\mathrm{O}$ bond axis as well as a node between the $\mathrm{P}$ and terminal $\mathrm{O}$ atom. Moreover, the $\pi^{*}$ orbital has a higher amplitude on the $\mathrm{P}$ atom than on the $\mathrm{O}$, as expected on the basis of the significant electronegativity difference (O has 3.5, $\mathrm{P}$ has 2.1) between $\mathrm{O}$ and $\mathrm{P}$. We can straightforwardly find and visually characterize a doubly occupied $\pi$ orbital for $\mathrm{MeO}-\mathrm{PO}$, which supports the use of the $\mathrm{P}^{0} \mathrm{O}^{0}$ valence-bond structure (consistent with $\mathrm{MeO}-\mathrm{P}=\mathrm{O}$ ) in Figure 4 rather than the dative $\mathrm{P}^{+} \mathrm{O}^{-}$structure. Moreover, the $\pi^{*}$ orbital shown here in Figure 5 looks much like that shown in Figure 4 of ref 1 where this same compound was put forth as one containing a PO $\pi$ bond, and again, we note that the experimental $\mathrm{P}=\mathrm{O}$ bond length ${ }^{11}$ $1.51 \AA$ is considerably shorter than the sum of the two atomic single-bond $\operatorname{radii}^{4}$ ( $0.66 \AA$ for $\mathrm{O}$ and $1.07 \AA$ for $\left.\mathrm{P}\right)$. Finally, we note that the $\pi^{*}$-attached anion $\mathrm{H}_{3} \mathrm{C}-\mathrm{O}-\mathrm{P}=\mathrm{O}^{-}$was found to be vertically stable by ca. $0.04 \mathrm{eV}$ at the MP2 level of theory within the basis set used in the present study, which means that the $\pi^{*}$ orbital is low lying, as expected.

B. Compound Containing the Phosphate Group. Let us now consider a compound in which phosphorus uses its $3 \mathrm{~s}$ and all three $3 \mathrm{p}$ orbitals to form $\sigma$ bonds but may (or may not) make use of its $3 d_{x, z}$ and $3 d_{y, z}$ orbitals to form a $\pi$ bond to an oxygen atom. In Figure 6 at the bottom, we again show the $\pi$ orbital of $\mathrm{MeO}-\mathrm{P}=\mathrm{O}$ discussed in the preceding section to facilitate comparison with the orbitals of the phosphate compound. At the top in Figure 6, we show the highest occupied molecular orbital (HOMO) of trimethyl phosphate $(\mathrm{MeO})_{3} \mathrm{PO}$ obtained using two different atomic orbital basis sets, one with no $\mathrm{d}$-functions on $\mathrm{P}$ and one with d-functions on P. Because this doubly occupied molecular orbital describes bound electrons, we did not have to use the charge stabilization technique to find these orbitals. It is important to also point out at this time that the $\mathrm{HOMO}$ of $(\mathrm{MeO})_{3} \mathrm{PO}$ is degenerate, and in Figure 6, we show only one member of the degenerate pair. The other member has the oxygen-centered orbital directed in and out of the plane of the figure rather than in the figure plane as shown in Figure 6. Referring to the axes used in Figure 4 to define directions, the HOMO we show in Figure 6 involves an $\mathrm{O} 2 \mathrm{p}_{y}$ orbital; the other member of the degenerate pair involves the $\mathrm{O}$ $2 \mathrm{p}_{x}$ orbital. 

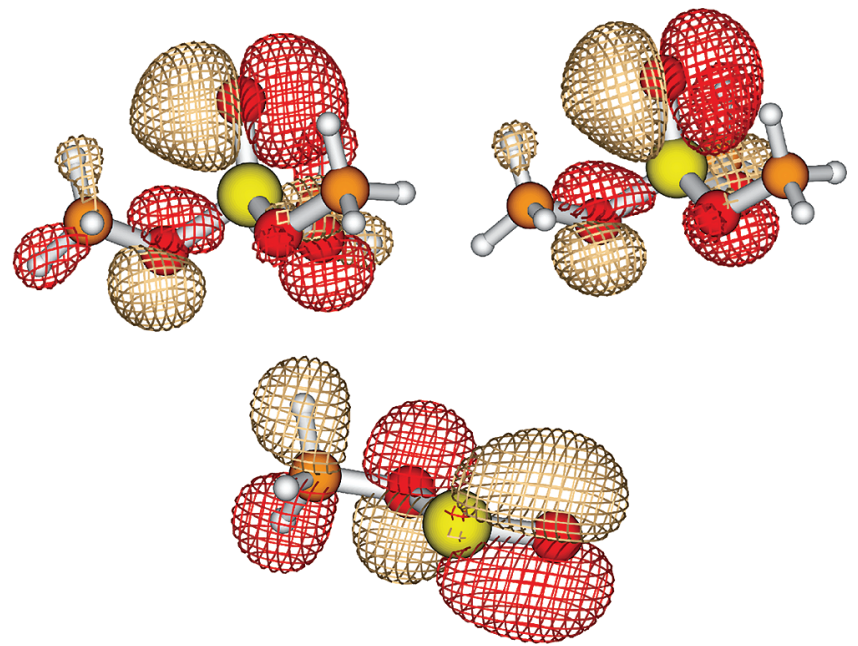

Figure 6. HOMO of (MeO) ${ }_{3} \mathrm{PO}$ (top) computed using the aug-cc-pVDZ basis set on phosphorus (right) and using the same basis set but with the d-polarization functions removed from the phosphorus atom (left). $\mathrm{HOMO} \pi$ orbital of $\mathrm{MeO}-\mathrm{P}=\mathrm{O}$ (bottom).

The $\mathrm{P}-\mathrm{OMe}$ distances in $(\mathrm{MeO})_{3} \mathrm{PO}$ turn out to be 1.62 and $1.66 \AA$ when the phosphorus d-polarization functions are present and absent, respectively, and the corresponding PO distances are 1.51 and $1.52 \AA$. In $\mathrm{MeO}-\mathrm{P}=\mathrm{O}$, the $\mathrm{P}-\mathrm{OMe}$ bond length is $1.66 \AA$, and the $\mathrm{P}=\mathrm{O}$ length is $1.52 \AA$. The (degenerate) HOMO orbital energies in $(\mathrm{MeO})_{3} \mathrm{PO}$ are -12.4 and $-12.5 \mathrm{eV}$ in the two basis sets, respectively. For $\mathrm{MeO}-\mathrm{P}=\mathrm{O}$, the $\mathrm{HOMO}$ orbital energy is $-12.6 \mathrm{eV}$. These findings suggest that whatever kind of $\mathrm{PO}$ bonding is operative in MeOPO is also operative in $(\mathrm{MeO})_{3} \mathrm{PO}$.

This comparison of the geometry and orbital-energy data obtained with the two basis sets suggests that the phosphorus atom's d orbitals contribute a small amount to forming the unique PO bond. We can see from the two pictures in the top of Figure 6 that the phosphorus d orbitals seem to allow the HOMO's electron density localized primarily in the unique oxygen atom's $2 \mathrm{p}_{y}$ orbital to distort more toward the phosphorus center. However, the delocalization of this HOMO into the space between the $\mathrm{O}$ and $\mathrm{P}$ atoms is somewhat less than that shown in the bottom of Figure 6 for the HOMO of $\mathrm{MeO}-\mathrm{P}=\mathrm{O}$, where we concluded earlier it is likely that the $\mathrm{P}$ and $\mathrm{O}$ are be involved in a $\pi$ bond. On the other hand, the fact that the $\mathrm{MeO}-\mathrm{P}$ and $\mathrm{PO}$ distances in $(\mathrm{MeO})_{3} \mathrm{PO}$ are nearly identical to those in $\mathrm{MeO}-\mathrm{P}=\mathrm{O}$ and that the $\mathrm{PO}$ distances in both compounds are much less than the sum of the single-bond $\operatorname{radii}^{4}(0.66 \AA$ for $\mathrm{O}$ and $1.07 \AA$ for $\mathrm{P}$ ) suggests that the unique $\mathrm{PO}$ bond in $(\mathrm{MeO})_{3} \mathrm{PO}$ involves more than a single $\mathrm{P}-\mathrm{O} \sigma$ bond to the terminal oxygen.

Now, let us try to determine which of the valence-bond structures shown in Figure 4 is dominant in $(\mathrm{MeO})_{3} \mathrm{PO}$. The nearly identical $\mathrm{PO}$ distances in $(\mathrm{MeO})_{3} \mathrm{PO}$ and in $\mathrm{MeO}-\mathrm{P}=\mathrm{O}$ tend to support the structures with formal charges $\mathrm{P}^{0} \mathrm{O}^{0}$ having one $\pi$ bond between $\mathrm{P}$ and $\mathrm{O}$, because the $\mathrm{P}^{0} \mathrm{O}^{0}$ structure was assumed to be dominant for $\mathrm{MeO}-\mathrm{P}=\mathrm{O}$. If the $\mathrm{P}^{-} \mathrm{O}^{+}$structure with two $\pi$ bonds were dominant, one would expect the PO bond length in the phosphate to be shorter than in $\mathrm{MeO}-\mathrm{P}=\mathrm{O}$, but it is not. If the $\mathrm{P}^{+} \mathrm{O}^{-}$dative structure $(\mathrm{MeO})_{3} \mathrm{P} \rightarrow \mathrm{O}$ with no $\pi$ bond dominated, it seems very fortuitous that the attraction between the $\mathrm{P}^{+}$and $\mathrm{O}^{-}$centers in that structure would be of just the right strength to make the PO bond length essentially the same as in $\mathrm{MeO}-\mathrm{P}=\mathrm{O}$, where a double bond is assumed to be present.
On the other hand, we could reject the existence of a $\pi$ bond in $\mathrm{MeO}-\mathrm{PO}$ and use the dative $\mathrm{P}^{+} \mathrm{O}^{-}$structures to describe both $\mathrm{MeO}-\mathrm{PO}$ and $(\mathrm{MeO})_{3} \mathrm{PO}$. In this case, we would assume the terminal-bond contraction in both compounds is due to the attraction between the $\mathrm{P}^{+}$and $\mathrm{O}^{-}$centers, which would give rise to some back-donation from one of the $\mathrm{O}^{-} 2 \mathrm{p}$ orbitals into the region of space near the $\mathrm{P}^{+}$. In our opinion, this scenario seems less likely given the clear $\pi$ and $\pi^{*}$ orbitals found for $\mathrm{MeO}-\mathrm{PO}$ (see Figure 5); in other words, these spatial distributions do not look like back-polarization from $\mathrm{O}^{-}$to $\mathrm{P}^{+}$but like real $\pi$ and $\pi^{*}$ orbitals. However, at this stage, we do not rule out the possibility of describing both species in terms of dative bonds and $\mathrm{P}^{+} \mathrm{O}^{-}$structures. Indeed, on pp 180-181 of Weinhold and Landis' book, ${ }^{12}$ it is argued that the bonding in $\mathrm{H}_{3} \mathrm{NO}$ should be viewed as involving a dative $\mathrm{N} \rightarrow \mathrm{O}$ bond having an NO bond order of ca. 1.08, whereas the PO bond in $\mathrm{H}_{3} \mathrm{PO}$ is assigned a bond order only slightly higher, 1.17. For these reasons, those authors ${ }^{12}$ prefer to use the dative $\mathrm{P} \rightarrow \mathrm{O}$ characterization of the bonding in these compounds. In addition, Reed et al. ${ }^{13}$ discuss bonding in $\mathrm{X}_{3} \mathrm{AY}$ compounds (including $\mathrm{F}_{3} \mathrm{PO}$ and $\mathrm{H}_{3} \mathrm{PO}$ ) and point out that back-donation from $\mathrm{O} 2 \mathrm{p}_{\pi}$ not into $\mathrm{P} 3 \mathrm{~d}_{\pi}$ but into $\mathrm{A}-\mathrm{X} \sigma^{*}$ orbitals may be the main source of PO bonding beyond the single $\sigma$ bond. We think this may be the case for compounds such as $\mathrm{F}_{3} \mathrm{PO}$ (which is focused on in ref 13) where the $\mathrm{P}-\mathrm{F} \sigma^{*}$ orbital is well positioned to accept the electron density from the $\mathrm{O} 2 \mathrm{p}_{\pi}$ orbital. However, it is not clear that this paradigm can apply when $\mathrm{X}$ is $\mathrm{MeO}$. Even if it were hyperconjugative back-donation such as ref 13 suggested rather than involvement of $\mathrm{P} 3 \mathrm{~d}_{\pi}$ orbitals, both perspectives conclude that the AY (i.e., PO) bonding involves more than a single bond. As we discuss later, we think a larger body of evidence (e.g., near identity in bond lengths and $\pi$ orbital energies in $\mathrm{MeO}-\mathrm{PO}$ and $(\mathrm{MeO})_{3} \mathrm{PO}, \mathrm{PO}$ bond-dissociation energies, $\mathrm{PO}$ vibrational frequencies, and dipole moment data) suggests that there is substantial PO $\pi$ bonding in phosphates.

Nevertheless, at this stage of our analysis, it seems most reasonable (to us) to use the $\mathrm{P}^{0} \mathrm{O}^{0}$ valence-bond structures to describe the bonding in phosphates such as $(\mathrm{MeO})_{3} \mathrm{P}=\mathrm{O}$. However, we emphasize that both $\mathrm{P}^{0} \mathrm{O}^{0}$ structures shown in Figure 4 must be used because they are degenerate in energy; no one structure is correct. In one of these two structures, the $\mathrm{O}$ atom uses a $2 \mathrm{p}_{x}$ orbital which (according to Figure 6) is polarized (using a bit of $\mathrm{P} 3 \mathrm{~d}_{x, z}$ orbital character) toward the $\mathrm{P}$ center; in the second structure, the $\mathrm{O}$ atom uses a $2 \mathrm{p}_{y}$ orbital that is polarized (by $\mathrm{P} 3 \mathrm{~d}_{y, z}$ ) toward the $\mathrm{P}$ center.

Since we tentatively concluded that it is appropriate to use the $\mathrm{P}^{0} \mathrm{O}^{0}$ valence-bond structure to describe phosphates as, for example, $(\mathrm{MeO})_{3} \mathrm{P}=\mathrm{O}$, it is instructive to reflect back on the case of the $\mathrm{CO}$ molecule to contrast its bonding to that in phosphates. For CO, we concluded earlier (actually, Linus Pauling did) that $\mathrm{CO}$ is best described as a combination of $10 \%$ $\mathrm{C}^{+} \mathrm{O}^{-}$(with no $\pi$ bonds), $50 \% \mathrm{C}^{-} \mathrm{O}^{+}$(with two $\pi$ bonds), and $40 \% \mathrm{C}^{0} \mathrm{O}^{0}$ (two equivalent structures each with one $\pi$ bond), the bonding in which is displayed in Figure 2. The fact that CO's bond length $(1.128 \AA)$ is much shorter than the sum of the single-bond $\operatorname{radii}^{4}(0.76 \AA$ for $\mathrm{C}$ and $0.66 \AA$ for $\mathrm{O})$ and shorter than the $\mathrm{C}=\mathrm{O}$ bond length ${ }^{11}(1.215 \AA)$ in acetone $(\mathrm{Me})_{2} \mathrm{C}=\mathrm{O}$ are supportive of Pauling's assignment of a bond order of 2.4 in $\mathrm{CO}$ and is supportive in writing $\mathrm{C} \equiv \mathrm{O}$ to describe its bonding. ${ }^{14}$ Likewise, the nearly identical $\mathrm{MeO}-\mathrm{P}$ and $\mathrm{PO}$ bond lengths found in $(\mathrm{MeO})_{3} \mathrm{PO}$ and $\mathrm{MeO}-\mathrm{P}=\mathrm{O}$ suggest that the two $\mathrm{P}^{0} \mathrm{O}^{0}$ valence-bond structures in $(\mathrm{MeO})_{3} \mathrm{PO}$ are dominant, because it is in these two structures that a single $\pi$ bond exists between $\mathrm{P}$ and $\mathrm{O}$. It is probably because of the larger 

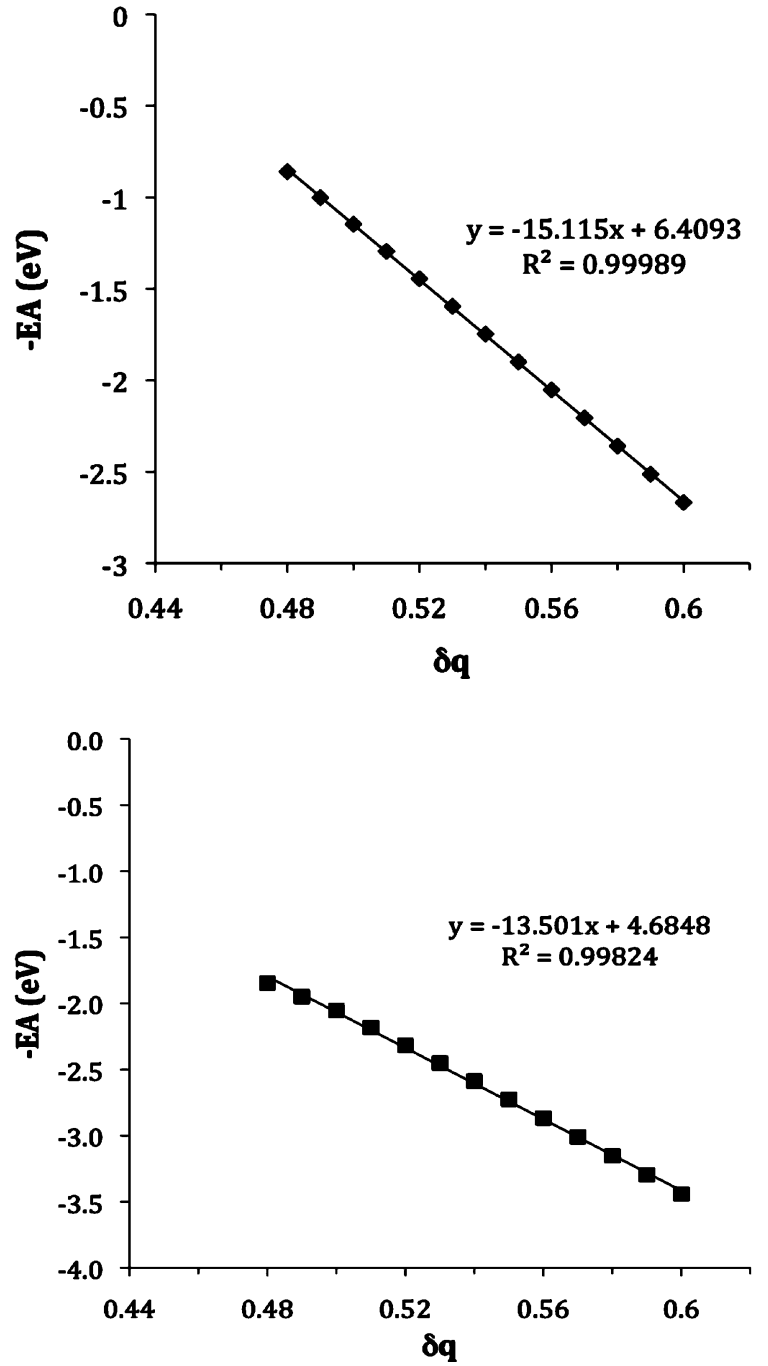

Figure 7. Plots of vertical electron affinities vs stabilizing charge $\delta q$ calculated at the Hartree-Fock (top) and UMP2 (bottom) levels for $(\mathrm{MeO})_{3}-\mathrm{PO}$ showing least-squares fits to $-E A=a+b \delta q$ with the statistical $R^{2}$ values.

electronegativity difference between $\mathrm{P}$ and $\mathrm{O}$ (2.1 vs 3.5) compared to $\mathrm{C}$ and $\mathrm{O}$ (2.5 vs 3.5 ) that the triple-bond $\mathrm{C}^{-} \mathrm{O}^{+}$ structure contributes strongly $(50 \%)$ in $\mathrm{CO}$ whereas the corresponding $\mathrm{P}^{-} \mathrm{O}^{+}$structure (which involves two $\pi$ bonds) does not in $(\mathrm{MeO})_{3} \mathrm{PO}$.

C. Where Is the PO $\pi^{*}$ Orbital? If, as we suggested above, it is proper to describe the bonding in phosphates in terms of the two $\mathrm{P}^{0} \mathrm{O}^{0}$ valence-bond structures corresponding to the $(\mathrm{MeO})_{3} \mathrm{P}=\mathrm{O}$ notation, it seems natural to expect to find a PObased $\pi^{*}$ orbital both when carrying out ab initio calculations on the $(\mathrm{MeO})_{3} \mathrm{P}=\mathrm{O}^{-}$anion (n.b., stabilization methods must be employed to avoid variational collapse) and in experiments such as the ETS experiments of ref 1 . As mentioned in the Introduction of this paper, there was no evidence in the ETS experimental data for any low-energy PO $\pi^{*}$ electron-attached state in phosphate-containing compounds. As part of the present work, we carried out charge-stabilization calculations using the methods detailed earlier to attempt to find and characterize a PO-localized $\pi^{*}$ orbital. In doing so, we added fractional charges $\delta q$ to only the $\mathrm{P}$ and terminal $\mathrm{O}$ nuclei to differentially stabilize virtual orbitals localized in the region of space near the $\mathrm{P}$ and $\mathrm{O}$ nuclei. As shown in Figure 7, where we show charge stabilization plots of the $(\mathrm{MeO})_{3} \mathrm{P}=\mathrm{O}$ anion-neutral energy

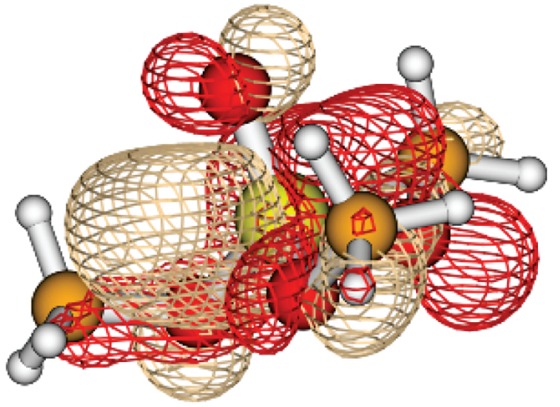

Figure 8. Possible PO $\pi^{*}$ orbital identified by adding charges $\delta q$ to only the $\mathrm{P}$ and $\mathrm{O}$ nuclei for $\delta q=0.5$.

difference, we had to use rather large values of $\delta q$ to obtain any electron-attached state that was electronically stable. In fact, there was only one such stable state identified even for such large $\delta q$ values. From past experience, the fact that a stable state is found only for large $\delta q$ values suggests that extrapolations to $\delta q \rightarrow 0$ to obtain an estimate of the energy of the anion state in the absence of stabilizing charges will have large energy uncertainties. Indeed, the extrapolated energies $(4.7 \mathrm{eV}$ for MP2 and $6.4 \mathrm{eV}$ for $\mathrm{HF}$ ) shown in Figure 7 seem very high (e.g., electron-attached states with an electron in a $\pi^{*}$ orbital of $\mathrm{N}_{2}$, $\mathrm{CO}$, or $\mathrm{H}_{2} \mathrm{CO}$ lie $2.3,{ }^{15} 2,{ }^{15}$ and $0.65^{16} \mathrm{eV}$ above their corresponding neutrals, and the $\pi^{*}$-attached state of $\mathrm{MeO}-\mathrm{PO}^{-}$ is even bound) for a $\pi^{*}$ orbital. Frankly, we do not believe these energy estimates to be at all reasonable for a putative $\mathrm{P}=\mathrm{O} \pi^{*}$ orbital. Instead, we can only conclude that we are not able to find a PO $\pi^{*}$ orbital in an energy range that makes sense, and below we discuss why this likely happens.

When we visually examine the orbital whose energies are plotted in Figure 7, we see an orbital (see Figure 8) that has significant amplitude in the PO region of space, whose POlocalized amplitude has a node between the $\mathrm{P}$ and $\mathrm{O}$ atoms with higher amplitude on the $\mathrm{P}$ atom but that is also highly delocalized over the remainder of the molecular framework. This orbital has essentially the same character for all $\delta q$ values used in the stabilization calculations.

It is important to note that the pictures of the putative PO $\pi^{*}$ orbital shown in Figure 8 were obtained from calculations with $\delta q$ incremental charges added to the $\mathrm{P}$ and $\mathrm{O}$ nuclei. Given how delocalized this orbital is, even with the (rather substantial) $\delta q$ charges acting to localize it near the $\mathrm{P}$ and $\mathrm{O}$ nuclei, it is clear that the corresponding electron-attached state will be even less PO-localized if we could find it by solving the electron-molecule Schrödinger equation in the absence of nuclear charge increments. We believe that coupling between the valence-range component of the $\pi^{*}$ state (whose orbital we think is represented qualitatively correctly in Figure 8) and the continuum states (corresponding to $(\mathrm{MeO})_{3} \mathrm{P}=\mathrm{O}$ plus a free electron) is so strong that this $\pi^{*}$-attached state is too short-lived to be experimentally observed. In other words, this state dissolves in the continuum to which it is strongly coupled. Although we are not certain what causes this state to have such a high energy, we believe it is likely due to strong repulsive interactions between the electron in this $\pi^{*}$ orbital and the doubly occupied (e.g., $\mathrm{P}-\mathrm{OMe} \sigma$, $\mathrm{O}-\mathrm{C} \sigma$, and $\mathrm{C}-\mathrm{H} \sigma$ ) orbitals of the nearby $\mathrm{P}-\mathrm{O}, \mathrm{O}-\mathrm{C}$, and $\mathrm{C}-\mathrm{H}$ bonds.

\section{Summary}

Our primary findings, taken with experimental data on bond lengths, orbital energies, bond energies, and dipole moments, combine to offer the following perspective: 
1. In $\mathrm{MeO}-\mathrm{PO}$, the $\mathrm{MeO}-\mathrm{P}$ bond length is $1.66 \AA$ and the PO length is $1.52 \AA$. The latter is qualitatively shorter than the sum of the $\mathrm{P}(1.07 \AA)$ and $\mathrm{O}(0.66 \AA)$ single-bond radii, which clearly suggests bonding beyond a single $\sigma$ bond.

2. In $\mathrm{MeO}-\mathrm{PO}$, a $\mathrm{PO} \pi$ orbital can be identified and has an orbital energy of $-12.6 \mathrm{eV}$. These two findings suggest using the $\mathrm{P}^{0} \mathrm{O}^{0}$ valence-bond structure and writing this molecule with a $\mathrm{PO} \pi$ bond as in $\mathrm{MeO}-\mathrm{P}=\mathrm{O}$.

3. The $\mathrm{MeO}-\mathrm{PO}^{-}$anion is bound (slightly) and has an electron in a $\pi^{*}$ orbital belonging to the terminal PO unit.

4. Depending on whether phosphorus d orbitals are or are not included in the basis set, in $(\mathrm{MeO})_{3} \mathrm{PO}$, the $\mathrm{MeO}-\mathrm{P}$ bond lengths are 1.62 or $1.66 \AA$, respectively, and the PO bond lengths are 1.51 or $1.52 \AA$. The shorter (i.e., $1.5 \AA$ ) bond lengths are qualitatively shorter than the sum of single-bond radii, which thus suggests some enhancement beyond a single PO $\sigma$ bond.

5. Visual inspection of the (degenerate) doubly occupied $\mathrm{HOMO}$ in $(\mathrm{MeO})_{3} \mathrm{PO}$ shows some $\mathrm{PO} \pi$ bonding character (e.g., a nodal plane containing the $\mathrm{P}-\mathrm{O}$ internuclear axis) with some delocalization over the $\mathrm{P}-\mathrm{O}$ internuclear region but less than in the $\pi$ orbital of $\mathrm{MeO}-\mathrm{PO}$. The HOMO obtained in a calculation using $\mathrm{d}$ basis functions on $\mathrm{P}$ is somewhat more polarized toward the $\mathrm{P}$ atom than when phosphorus $\mathrm{d}$ orbitals are excluded.

6. The $\mathrm{HOMO}$ orbital in $(\mathrm{MeO})_{3} \mathrm{PO}$ has an energy of -12.4 $\mathrm{eV}$ when $\mathrm{d}$ basis functions are included on the $\mathrm{P}$ atom and -12.5 $\mathrm{eV}$ when the $\mathrm{d}$ basis functions are excluded. These are close to the energy $(-12.6 \mathrm{eV})$ of the $\mathrm{PO} \pi$ orbital in $\mathrm{MeO}-\mathrm{PO}$.

7. The near identity of the $\mathrm{PO}$ (and $\mathrm{MeO}-\mathrm{P}$ ) bond lengths and $\mathrm{HOMO}$ orbital energies in $\mathrm{MeO}-\mathrm{PO}$ and $(\mathrm{MeO})_{3} \mathrm{PO}$ and the fact that the PO bond lengths are shorter than the sum of single-bond radii suggest that whatever kind of $\mathrm{PO}$ bonding is operative in $\mathrm{MeO}-\mathrm{PO}$ is also operative in $(\mathrm{MeO})_{3} \mathrm{PO}$. Because it appears a $\mathrm{PO} \pi$ bond is active in $\mathrm{MeO}-\mathrm{PO}$, we conclude one must also exist in $(\mathrm{MeO})_{3} \mathrm{PO}$.

On the basis of all of these reasons, we prefer to describe the $\mathrm{PO}$ bonding in the $(\mathrm{MeO})_{3} \mathrm{P}=\mathrm{O}$ notation but realize that two degenerate valence-bond structures (the two $\mathrm{P}^{0} \mathrm{O}^{0}$ structures in the second row of Figure 4) are implied in this notation. In these structures, the $\mathrm{P}$ atom seems to make a small amount of use of its $3 d_{x, z}$ and $3 d_{y, z}$ orbitals (one for each of the two degenerate valence-bond structures).

Finally, if one argues for describing the $\mathrm{PO}$ bonding in $(\mathrm{MeO})_{3} \mathrm{PO}$ in terms of the $\mathrm{P}^{+} \mathrm{O}^{-}$dative $(\mathrm{MeO})_{3} \mathrm{P} \rightarrow \mathrm{O}$ structure, the geometry and orbital energy data discussed above argue that one should then also describe $\mathrm{MeO}-\mathrm{PO}$ in this same way (i.e., in terms of the third structure in the top row in Figure 4). The contraction of the $\mathrm{PO}$ bond in $\mathrm{MeO}-\mathrm{PO}$ would then be attributed to attraction between $\mathrm{P}^{+}$and $\mathrm{O}^{-}$, which generates some back-donation from an $\mathrm{O}^{-} 2 \mathrm{p}$ orbital toward the $\mathrm{P}^{+}$region. In our opinion, not only does the visual evidence of $\pi$ and lowlying $\pi^{*}$ orbitals in $\mathrm{MeO}-\mathrm{PO}$ argue against these assignments but also the following data do.

1. The dipole moment ${ }^{17}$ of $\mathrm{Me}_{3} \mathrm{~N} \rightarrow \mathrm{O}$, where the existence of a dative NO bond is accepted and where no NO $\pi$ bond is possible (unlike $\mathrm{P}, \mathrm{N}$ has no d orbitals to use), is $5.02 \mathrm{D}$ and that of the analogous phosphorus compound $\mathrm{Me}_{3} \mathrm{PO}$ is less (4.37 D). If the $\mathrm{PO}$ bond in $\mathrm{Me}_{3} \mathrm{PO}$ were dative, one would expect the dipole moment of $\mathrm{Me}_{3} \mathrm{PO}$ to be greater than that of $\mathrm{Me}_{3} \mathrm{NO}$, because $\mathrm{P}$ is much less electronegative than $\mathrm{N}$ (2.1 vs 3.0).

2. The $\mathrm{PO}$ bond dissociation energies ${ }^{18}$ in compounds containing the phosphate motif (e.g., $\mathrm{Me}_{3} \mathrm{PO}$ and $(\mathrm{MeO})_{3} \mathrm{PO}$ ) are in the $500-600 \mathrm{~kJ} \mathrm{~mol}^{-1}$ range, while the $\mathrm{NO}$ bond energies in compounds such as $\mathrm{Me}_{3} \mathrm{NO}$ are ca. $200-300 \mathrm{~kJ} \mathrm{~mol}^{-1}$. The former are certainly stronger than expected for a single bond, while the NO bond energies are in line with those of a single bond. In contrast, the $\mathrm{P}-\mathrm{OMe}$ bond energy ${ }^{19}$ is only ca. $88 \mathrm{kcal}$ $\mathrm{mol}^{-1}$.

3. The PO stretching vibrational frequencies ${ }^{18}$ observed in IR spectra of $\mathrm{X}_{3} \mathrm{PO}$ compounds range from 1176 to $1404 \mathrm{~cm}^{-1}$, with the higher frequencies arising when $\mathrm{X}$ is electron withdrawing (e.g., $\mathrm{F}$ or $\mathrm{Cl}$ ) and the lower frequencies when $\mathrm{X}$ is electron donating (e.g., $\mathrm{MeO}$ ). If $\mathrm{X}_{3} \mathrm{PO}$ involved dative $\mathrm{PO}$ bonding having $\mathrm{P}^{+} \mathrm{O}^{-}$formal charges, electron donating (withdrawing) would be expected to strengthen (weaken) the PO bond, which was the opposite of what the IR frequencies indicate.

In summary, the preponderance of the evidence (geometric, orbital energy, orbital pictures, PO IR frequencies, PO bond energies, and dipole moments) points toward the existence of a (weak, as expected between two atoms from different rows of the periodic table) PO $\pi$ bond in phosphates. The PO $\pi^{*}$ orbital (more accurately, the $\pi^{*}$-attached anion state corresponding to it) has not been detected in recent experiments, ${ }^{1}$ and its valencerange component's energy is only tentatively (because of large uncertainties in having to extrapolate over large values of $\delta q$ ) identified in our stabilization calculations. It is our opinion that these PO $\pi^{*}$ states are so strongly coupled to the continuum states with which they are degenerate as to render them so short lived as to be undetected in ETS. In contrast, the $\pi^{*}$-attached state of $\mathrm{MeO}-\mathrm{P}=\mathrm{O}$ was found to be electronically stable. What causes the phosphate PO $\pi^{*}$ states to be shifted to such high energies is not clear to us at this time, although inspection of the orbital shown in Figure 8 suggests that the spatial overlap of this orbital (and thus Coulomb repulsion) with several doubly occupied $\mathrm{P}-\mathrm{OMe} \sigma$ orbitals $(\mathrm{P}-\mathrm{O}, \mathrm{O}-\mathrm{C}$, and $\mathrm{C}-\mathrm{H})$ could be what pushes this orbital to a higher energy and gives its electronattached state a short lifetime.

We, therefore, conclude that phosphates can be described as having a $\mathrm{P}=\mathrm{O} \pi$ bond with an associated doubly occupied $\mathrm{PO}$ $\pi$ orbital, but the $\pi^{*}$ orbital arising in the $\pi^{2} \pi^{* 1}$ electronattached state is so strongly coupled to other orbitals that it is pushed to a higher energy, dissolves into the continuum, and thus, is difficult if not impossible to detect in ETS experiments.

Acknowledgment. Support of the National Science Foundation through Grant CHE 0806160 is appreciated. Significant computer time was provided by the Center for High Performance Computing at the University of Utah. J.S. thanks reviewers of earlier attempts at this manuscript for constructive input.

\section{References and Notes}

(1) Burrow, P. D.; Gallup, G. A.; Modelli, A. J. Phys. Chem. A 2008, $112,4106-4113$.

(2) Pauling, L. The Nature of the Chemical Bond, 3rd ed., 5th printing; Cornell University Press: Ithaca, NY, 1964.

(3) Herzberg, G. Molecular Spectra and Molecular Structure, I. Spectra of Diatomic Molecules; Van Nostrand Reinhold Co.: New York, NY, 1950.

(4) Cordero, B.; Gómez, V.; Platero-Prats, A. E.; Revés, M.; Echeverría, J.; Cremades, E.; Barragán, F.; Alvarez, S. Covalent radii revisited. Dalton Trans. 2008, 2832-2838. DOI: 10.1039/b801115j.

(5) This structure is known to undergo rearrangement from $(\mathrm{HO})_{3} \mathrm{P}$ to $(\mathrm{HO})_{2} \mathrm{HP}=\mathrm{O}$ (i.e., to phorsphorous acid with one $\mathrm{H}$ atom bonded to the $\mathrm{P}$ ).

(6) Kendall, R. A.; Dunning, T. H., Jr.; Harrison, R. J. J. Chem. Phys. 1992, 96, 6796-6806.

(7) Even the Møller-Plesset perturbation approach used here begins by performing a Hartree-Fock (HF) calculation (on the neutral and on the anion), and the HF process is subject to variational collapse.

(8) This device was first used in: Nestmann, B.; Peyerimhoff, S. D. J. Phys. B 1985, 18, 615-626, 4309-4319. We created a web site (http:// www.hec.utah.edu/G03supplement) in which we demonstrate how one can carry out such charge stabilization calculations within the widely used Gaussian program suite. 
(9) Frisch, M. J.; Trucks, G. W.; Schlegel, H. B.; Scuseria, G. E.; Robb, M. A.; Cheeseman, J. R.; Montgomery, J. A., Jr.; Vreven, T.; Kudin, K. N.; Burant, J. C.; Millam, J. M.; Iyengar, S. S.; Tomasi, J.; Barone, V.; Mennucci, B.; Cossi, M.; Scalmani, G.; Rega, N.; Petersson, G. A.; Nakatsuji, H.; Hada, M.; Ehara, M.; Toyota, K.; Fukuda, R.; Hasegawa, J.; Ishida, M.; Nakajima, T.; Honda, Y.; Kitao, O.; Nakai, H.; Klene, M.; Li, X.; Knox, J. E.; Hratchian, H. P.; Cross, J. B.; Bakken, V.; Adamo, C.; Jaramillo, J.; Gomperts, R.; Stratmann, R. E.; Yazyev, O.; Austin, A. J.; Cammi, R.; Pomelli, C.; Ochterski, J. W.; Ayala, P. Y.; Morokuma, K.; Voth, G. A.; Salvador, P.; Dannenberg, J. J.; Zakrzewski, V. G.; Dapprich, S.; Daniels, A. D.; Strain, M. C.; Farkas, O.; Malick, D. K.; Rabuck, A. D.; Raghavachari, K.; Foresman, J. B.; Ortiz, J. V.; Cui, Q.; Baboul, A. G.; Clifford, S.; Cioslowski, J.; Stefanov, B. B.; Liu, G.; Liashenko, A.; Piskorz, P.; Komaromi, I.; Martin, R. L.; Fox, D. J.; Keith, T.; Al-Laham, M. A.; Peng, C. Y.; Nanayakkara, A.; Challacombe, M.; Gill, P. M. W.; Johnson, B.; Chen, W.; Wong, M. W.; Gonzalez, C.; Pople, J. A. Gaussian; Gaussian, Inc.: Wallingford, CT, 2004.

(10) Schaftenaar, G.; Noordik, J. H. J. Comput. Aided Mol. Des. 2000, 14, 123.
(11) Herzberg, G. Molecular Spectra and Molecular Structure, II. Electronic Spectra of Polyatomic Molecules; Van Nostrand Reinhold Co.: New York, NY, 1966.

(12) Weinhold, F.; Landis, C. R. Valency and Bonding; Cambridge University Press: Cambridge, U.K., 2005.

(13) Reed, A. E.; Schleyer, P.; von, R. J. Am. Chem. Soc. 1990, 112, 1434-1445.

(14) Given the bond order of 2.4, it seems equally valid to write $\mathrm{C}=\mathrm{O}$ to describe the bonding.

(15) Schulz, G. J. Rev. Mod. Phys. 1973, 45, 423-485.

(16) Burrow, P. D.; Michejda, J. A. Chem. Phys. Lett. 1976, 42, 223226.

(17) Huheey, J. E. Inorganic Chemistry, 3rd ed.; Harper and Row: New York, NY, 1983; p 826.

(18) Huheey, J. E.; Keiter, E. A.; Keiter, R. L. Inorganic Chemistry, 4th ed.; Harper, Collins: New York, NY, 1993; p 869-870.

(19) Purcell, K. F.; Kotz, J. C. Inorganic Chemistry; W. B. Saunders Co.: Philadelphia, PA, 1977; p 332.

JP810014S 